\section{Researching event-centred projects: Showcasing grounded aesthetics}

Frances Howard (D)

Nottingham Trent University, UK

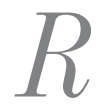

Qualitative Research

$1-19$

(C) The Author(s) 2021

(c) (i)

Article reuse guidelines: sagepub.com/journals-permissions DOI: 10.1 I77/I468794I21990973 journals.sagepub.com/home/qrj

๑SAGE

\begin{abstract}
Showcasing plays a fundamental role in arts education programmes. This paper presents an approach to research scenarios which explore 'event-centred' projects. Drawing on arts-based methodologies and research projects, this approach could be extended to the study of seasonal rituals, festivals and other types of organisational settings in which creative work culminates in some type of public display. This paper defines the key features of this method, which draw on Paul Willis' concept of 'grounded aesthetics' and Sarah Pink's work on the sensorial and embodied experience. I discuss the experimentation with various digital media and documentation strategies which adopt a participatory and collaborative perspective. I focus on how the sensorial, multimodal and collaborative approaches to ethnography are used within event-centred research projects which complement more 'traditional' ethnographic approaches. Finally, this paper offers a methodological contribution regarding how to unpack the 'grounded aesthetics' of specific contexts and communities.
\end{abstract}

\title{
Keywords
}

Ethnography, Performing, Multimodality, Youth, Arts education, Digital ethnography, Grounded Aesthetics, Embodied experience

\section{Introduction}

Showcasing plays a fundamental role in arts education programmes. Sensorial, multimodal and collaborative approaches to ethnography have been well documented. This paper explores what happens when these approaches come together in order to enable a deeper investigation into the experience of participating in 'event-centred' projects. With a focus on the performance as central, ethnographic fieldwork is conducted as part of a

\section{Corresponding author:}

Frances Howard, Department of Social Work, Care \& Community, Nottingham Trent University, 50 Shakespeare Street, Nottingham NGI 4FQ, UK.

Email: Frances.Howard@ntu.ac.uk 
cycle, which seeks to recognise and privilege participants' learning through participating in events. Drawing on arts-based methodologies and research projects, this approach could be extended to the study of seasonal rituals, festivals and other types of organisational settings in which creative work culminates in some type of public display. More than simply participant-observation, this approach is based in youth work practice, which involves the development of supporting relationships in order to generate rich data (Curtis et al., 2004). This paper explores a specific approach which engages with grounded aesthetics, the embodied experience and the resulting opportunities for collaborative and participatory analysis.

Whilst ethnography is a critical approach that acknowledges and records the sensory nature of human experience, this presents a challenge in regard to recognising and valuing diverse cultural experiences. In response, in this paper I engage with 'grounded aesthetics' (Willis, 1998b) as a way to unpack the cultural values of specific localised communities. I highlight the importance of the embodied experience (Pink, 2015) in being responsive to, and inclusive of, varying social contexts. I give details on the research study of which this particular approach was a component, within a larger ethnographic project. I discuss experimenting with various media and documentation strategies which adopt a participatory and collaborative perspective. Finally I argue that for this approach in forefronting lived experience, acknowledging diverse cultures and challenging the representation of knowledge through ethnographic research.

This paper gives details on the practical considerations of ethnography in relation to young people's performance of singing, rapping and DJing at live music events. As part of my doctoral research investigating young people's educational experiences of a vocational arts programme, I utilised ethnography as an approach to explore what the young people got out of performing, their motivations for taking part in these events and what young people valued about these experiences. I focused on three showcase events, taking place in three different settings (a dis-used bar, a theatre venue and an over 18s nightclub). The culture of performing at each of these events was noticeably different. My interest was in developing an approach that would acknowledge, capture and represent this difference. This required fieldwork in addition to the ten hours spent at the events, as I worked with participants prior to and following the events over 40 additional hours. I generated data through fieldnotes, short notes taken on a mobile phone, audio and video recordings. These were all shared with participants as aide memoires, which enabled them to talk about their experience and enabled a series experiential outputs, in the form of short film clips. The process, project and participants will be presented fully below.

\section{Ethnography of 'event-centred' projects}

Whilst the collation of a wide range of data through visual and multimodal methodologies are well accepted practices within ethnography, less attention has been paid to 'audiencing' (Rose, 2012), which acknowledges the significance of the exhibiting or performance phase of research projects (Delgado, 2015). A focus on the embodied and culturally specific aspects of performance events is lacking. Mitchell's work (Nyariro et al., 2017) on exhibiting the production of images as part of photovoice, in particular, argues for the value of documenting responses to an exhibition across multiple showings. 
This approach is taken up by this paper, which explores performances across three different venues.

As well as researching arts experiences, ethnography has a long history as a methodology that is drawn upon to undertake research with young people (Curtis et al., 2004; Finlay et al., 2013; Russell, 2013). This is due to its responsive and adaptive approach to both the diverse spheres young people inhabit and the diversity of youth cultures. I intended that my approach share these advantages, in order to explore young people's educational experiences of a vocational arts programme, which was the focus of my study. In addition, my approach was influenced by youth work practice (Gormally and Coburn, 2014) where spending time with young people across various contexts, such as their informal arts networks, gatherings and gigs, was a key part of the research process.

These showcasing events offer opportunities for participatory analysis where researchers work with visual texts as tools for dialogue (Theron et al., 2011). Going 'beyond engagement' the use of visual methodologies within ethnography expand the life and use of visual productions so that the enable meaningful participation (Mitchell et al., 2016). Appearing in digital form, the artefacts collated and generated within this research were rooted in both online and offline contexts. Where young people take ownership of their performance events and digital outputs resulting from them, they become co-constructors of knowledge across the various sites (Gallagher et al., 2013). Throughout this paper, examples are given of where the live and digital combine and how participant-created video texts reveal narrative constructions and multiple perspectives within young people's lives.

\section{Embodiment and emplacement}

Whilst digital ethnography offers new ways of recording, analysing, sharing and presenting data (Ardèvol and Gómez-Cruz, 2012), the embodied presence of the researcher in the field, as a more 'traditional approach' serves as compliment. Experiencing events together with participants was a way of developing mutual understanding, shared experiences and a springboard for the reflective dialogue that follows the event. My intention was a participatory practice framed with ideas of learning as embodied, emplaced, sensorial and empathetic, rather than occurring simply through a mix of participation and observation (Pink, 2015). In addition, the embodied experience was key to my approach due to the engagement and reflexivity required of the researcher in order to understand the participants' own experiences. Degarrod (2013) argues for the social and dialogical process of the creation of embodied knowledge, which is strengthened through the understanding and empathy developed with participants through the sharing of mutual memories, images, and sentiments. Therefore, the embodied experience enabled me to generate data as a springboard for the contrasting and comparison of experience with the participant-performers.

Building upon strong research traditions of utilising ethnography to research cultural practices, which focus on feelings, emotions and the meaningfulness of arts experiences (Heath and Roach, 1999; Hickey-Moody, 2013; Jeffrey, 2006; Thomson and SeftonGreen, 2010), my approach engaged with arts-based methodologies. Arts practice, in recent years, has become increasingly central as a means of both creating new embodied 
ways of knowing and producing scholarly narrative (Pink et al., 2010). Alternative approaches to representing sensory knowing have been developed and there are opportunities for these practices to both inform and be developed collaboratively with sensory approaches to ethnographic representation (Pink, 2015). Through 'experimental collaborations' (Estalella and Criado, 2018) merely observational modes of research are transformed into collective explorations and co-documentation. This is often afforded through the use of digital technologies, which are increasingly used as the tools for the production of knowledge.

Within ethnography, visual technologies, such as photography, film and audio recordings, can be used for data capture. The resulting multimedia data sets offer affective vehicles for participants' diverse modes of communication and the embodied experience. The affordances of this approach offer new possibilities for meaning making and different modes for learning (Flewitt, 2011). Drawing on multimodal ethnography (Dicks et al., 2006) where a wide range of artefacts are collated, which aide analysis and representation of the experience. Engaging with multimodality enabled a heightened awareness and ability to represent the embodied experience through an assemblage approach to meaning-making (Lamb et al., 2018). In response, my approach captured multimodal data, for its value in representing and co-producing the participants' experience in experiential form as part of the analysis. A shift from theories of embodiment to one of emplacement (Ingold, 2011) has been seen as an advantage for recognising the competing/performing body as part of an ecology of things, encompassing both the specificity and intensity of the place event (Pink, 2011). When conducting ethnographic research that incorporates embodiment and feeling, such as experiencing the arts alongside participants, a shared framed of reference is required. In response, this paper engages with grounded aesthetics as a way to interpret performances within specific cultural and social contexts.

\section{Grounded aesthetics}

Ethnography places an emphasis on experience-related data collection and experiencing the world of others, 'being there' and 'doing things' through participation (Jones, 2002; Pink, 2015; Russell, 2013). During my fieldwork, I needed to understand what was culturally specific to my participants, their repertoire of cultural values, which influenced their experience of performing at events. I drew on Paul Willis' concept of grounded aesthetics as a way of recognising a 'bottom-up' approach to defining cultural meanings (Willis, 1998b). He argues that particular codes of value, meaning and hierarchies are developed that are specific to particular groups of people, and in this case, the young people who were the participants in the live music events. My intention, therefore, was to explore participants' displays of grounded aesthetics through performing as a way of critically judging experiences that are shared with others as a form of social practice.

Grounded aesthetics are a form of embodied knowledge, encompassing the knowable but unsayable, the unspoken rules of performing and ways of being at performance events. There is a long-standing tradition of performances as part of music-making among young people, where grounded aesthetics are used to critically judge their experience and share their culture with others drawing on symbolic creativity (Bennett and 
Peterson, 2004; Jones, 1990; Willis, 1998a). In asking one performer what made a good rap (their preferred musical style), they reported criteria such as the ability to 'spit' lyrics really fast, having swagger or presence on stage, not 'choking' and performing your own lyrics. These judgement criteria are not officially recorded in the music 'scene' but are instead directly derived from the participants, their previous experiences, expectations and motivations for their own performances. There is no curriculum or written rules for these events, but there are ways of being, ways of performing and hierarchies that are dictated by the performers and the events in which they place themselves.

My approach was a way to access and to recognise these repertoires of grounded aesthetics. Investigating participants' expectations of and criteria for judging the events was an important way of gleaning an alternative perspective on their experiences. Lucy Green's work, which explores informal music-making, reminds us that we are totally enmeshed in a social and cultural world, where often we 'forget' the grounds on which our behaviour is based (O'Neill and Green, 2001). In the performance of music, on which this paper is based, there is an opportunity to make visible these often taken-for-granted routines, practices and tastes, which the sensory and relational aspects of grounded aesthetics can be used to capture.

Each of the three events I was exploring were organised for young people to perform as part of this arts programme. The intention was to showcase their talents to their peers, parents and the wider community of young people. The grounded aesthetics and cultures of performing were different at each of these events and my engagement with ethnography was a way of investigating the different reasons performers had chosen to perform and the perceived value for them. I was also able to recognise the different practices of performing engendered by the different venues, from the smoke-filled and close environment of the nightclub venue to the more traditional performance on stage at the theatre venue. Trying to raise my awareness to participants' grounded aesthetics prior to the event was part of the process of beginning to feel familiar with events of which I had no prior experience. For example, the rap battle was the most alien environment for me. In sharing my ethnographic encounters and my approach to researching event-based projects, I attempt to offer applicable examples which could be extended to the study of gigs, festivals and exhibition as the performative culmination of projects in which participants are involved. First, I give further details on the larger ethnographic project of which this particular approach was a component.

\section{The study}

This paper reports on an approach adopted to particular performance-event settings which were a part of a larger ethnographic study. The wider study sought to investigate the educational experiences of 'dis-engaged' young people undertaking a vocational arts programme, based in England. The participants were categorised as 'dis-engaged' due to their dejection of, or rejection from, mainstream schooling. For them, their engagement with this programme was through either alternative or informal education settings, which included a mix of compulsory and voluntary attendance. The vocational arts programme being researched was the Arts Award ${ }^{1}$ : a national qualification, which supports young people to 'grow as artists and arts leaders, connecting them with the wider arts world 
through setting personal challenges in an art form of their choice' (Arts Award, 2016). As part of this programme, young people are required to create and share work created from a range of artforms, which often results in showing through either exhibition or performance. Therefore, this paper explores the particular ethnographic methods for researching the live music performances created as part of this particular programme.

The sites of study were located with the East Midlands region of England, all situated in an urban area with high levels of deprivation, school exclusions and youth unemployment. The broader study engaged with five different 'youth' projects within the locality over the period of a year. This ethnographic study followed five Arts Award projects, observing the projects and their arts activities, recording the experience of the young people on their programmes. These projects were selected to encompass a variety of artforms - dance, music, visual arts, and digital media and a range of levels - Bronze, Silver and Gold. ${ }^{2}$ They were chosen due to the nature of the participants regarded as 'disengaged' young people and the delivery methods of the award, which were informal. The projects fell into three settings: further education, alternative education and youth projects. A conscious decision was made to avoid the formal education sector and schools who run the award, often for gifted and talented students as well as avoiding arts organisation who run the award for young people, often with strong arts backgrounds. The sample for this study was made up of, in particular, non-formal and non-arts background young people, aged between 14 and 23 years.

Sampling the different educational settings of Arts Award programmes was an important element of the research. Spending time with young people in the informal environments where they took part in their arts practice such as youth centres, local venues and nightclubs was also critical. This was done through two perspectives: experiencing arts education in informal or vocational settings and experiencing the arts as part of participants' everyday lives by attending arts events and performances with the young people. This provided data for the comparison of these situations and to gain insights relating to the settings, understanding the networks that shape the social (Mills and Morton, 2013). It meant that as a researcher, adapting to these differing environments as the young people did, was another way of building rapport and trust to be able to be invited to these spaces.

The three events explored in this paper were organised, often with participants, as an end of project showcase. All events had a focus on young talent and the opportunity to demonstrate artistic and communication skills, which participants argued for as valuable in relation to 'making yourself heard'. A disused bar, a theatre venue and an over 18s nightclub, were the settings for the three events. As well as the time spent attending these events, I spent additional hours prior to and following as part of the ethnographic process. Data generated included reflective fieldnotes, short notes taken on a mobile phone, audio and video recordings, which were all key to the stage following the event to enable co-production of representational and experiential outputs. Particular research processes were designed so that young people's first-hand experience of the programmes could be highlighted. These included experiencing together and film making as collaborative analysis. The use of creative methods was important for exploring the experience of others, but also to enable alternative methods of representation. This study engaged with the arts as a strategy for research as well as a concern for 'voice', alongside approaches such as 'talk around art' (Biggs, 2002; Mäkelä, 2007) in order to be responsive to the young people. 
The overall study included 46 young people, across five different settings. However, not all were engaged in performing, therefore this element of the research was focused on six participant-performers in particular. They included:

- $\mathrm{Greg}^{3}$, a male Project Worker, with a performance background, who was in two bands

- Pete, a 23-year-old male Grime artist and battle rapper

- JB, an 18-year-old male rapper / singer, who attended college part time

- Serena, a 14-year-old female rapper, still in school, who attended an open-access music project

- Grace, a 15-year-old female singer, just left school, who attended a referral music project for young people in 'challenging circumstances'

- Tyrone, a 16-year-old male DJ, who attended alternative education provision

Alongside these approaches, more traditional ethnographic methods were used such as participant observation, participation in arts activities and one-to-one interviews of an informal manner. Furthermore, in order to explore the embodied experience of performing multimodal data sources were generated engaging with arts-based research methods such as photography, collage, lyric writing and filmmaking. These creative activities were often embedded with the young people's Arts Award programmes and generated alternative data sets from which to reflect upon the participants' experiences. As well as being a springboard for conversation the artistic methods produced a range of creative data and other arts-based artefacts such as the young people's Arts Award portfolios, which were analysed as data sets in themselves. This included artistic work created by the young people such as music, lyrics, films and visual artwork, as well as attending performance events. Using this assortment of methods alongside ethnography captured additional dimensions, generated a greater depth of data and allowed for a deeper understanding of the participants' experiences of showcase events.

In order to explore young people's experience of an arts education programme, creative and visual outputs from its participants were considered as data. Where the use of creative methods is important for exploring the experience of others, it is also important for communicating the key messages and arguments within the thesis and as part of the dissemination of research. The use of visual and audio material is vital for the unpacking of meaning within this research and to communicate its messages. Therefore, this paper presents visual vignettes (Barter and Renold, 1999) in the form of montages of event flyers and fieldnotes to be evocative. By juxtaposing images and fieldnotes as an assemblage of digital media and text that is designed to represent the multifaceted perspectives within the data. These creations are both representative of the young people's experiences, but also acknowledge a different way of knowing that the arts encompasses. In addition, five film clips were created with participants with the intention that they assist in representing the young person's experience and the participatory analysis process. The empirical examples presented in this paper make a contribution to the use of 'presentational' or symbolised knowing (Liamputtong and Rumbold, 2008) representing experiential learning in expressive forms, which is a relatively underdeveloped area in academic research. 


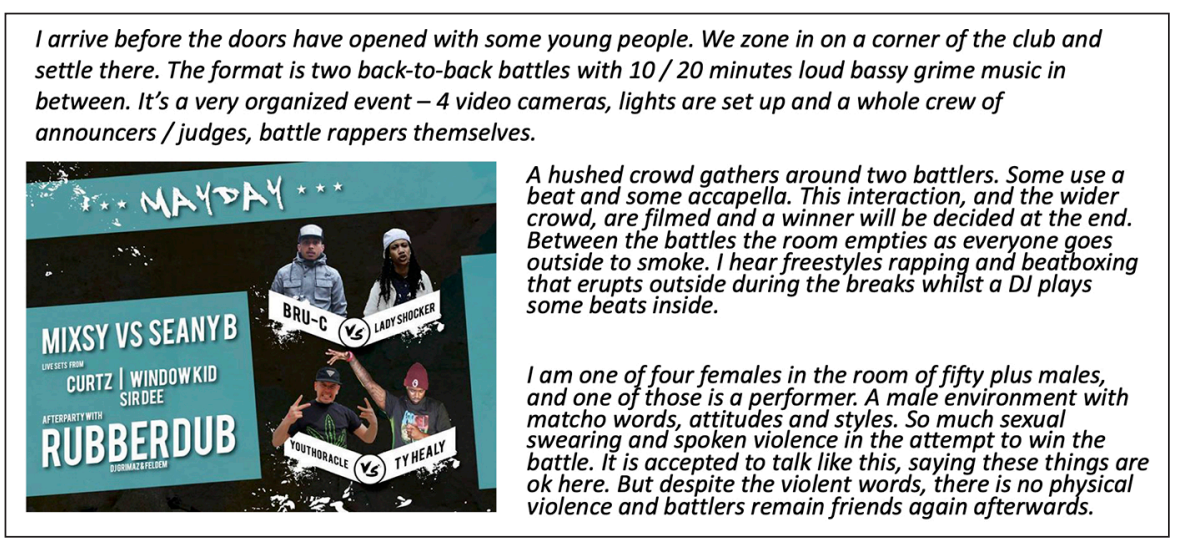

Figure I. Event flyer 'mayday' with fieldnotes.

\section{Researching 'event-centred' projects}

My approach to investigating the values young people ascribed to performing at live music events required more than simply attending the event as an audience member. I was aware that I required time with participants before events to begin to develop an understanding of their 'grounded aesthetics' (Willis, 1998b). As outsiders and ethnographers, it is not always immediately possible to recognise what others value as part of their own subjective experiences. My second concern was the capturing of a wider variety of data during the event, which would enable multimodal representation and an embodied understanding of performing. Following the event, I had hoped to adopt a participatory and collaborative approach to analysis, both as a means for reflection about the experience of performing alongside the participants, and for representing experiential data in expressive forms. My approach, as well as focusing on how the sensorial, multimodal and collaborative approaches to ethnography, are used within event-centered research projects, experimented with various digital media and documentation strategies. Therefore, I offer the following examples of this approach and advocate for it as enabling a deeper understanding of participants' experiences of showcasing events as an exploration of the 'grounded aesthetics' of specific contexts and communities more widely.

\section{The embodied and sensorial experience}

Being 'prepared' is a key stage of ethnography, which can be undertaken not by the researcher in isolation, but in collaboration with the performers in this particular context. Before each event I wanted to explore participants' prior experiences of similar events, as well as their expectations. For example, the first event I attended was a rap battle at a night club venue, shown in Figure 1. I was accompanying two participants: Pete, a 23-year-old Grime artist and battle rapper and Tyrone, a 16-year-old aspiring DJ. As a distinct 'outsider' to the rap music scene through age, appearance and gender, it was useful to be made aware of what happens at these events. Before this event in particular, Pete and Tyrone, shared several clips on YouTube of previous events. Watching previous rap battles together 
I arrive at the Playhouse, which is full of well-dressed regular theatre goers about to go into a Saturday night performance. I wonder where the young people's gig is and where they are. The crowds disperse and I see some of them coming into the venue ...

CULTURAL VIBRATIONS PRESENTS

LIVE \& LOCAL 2.0

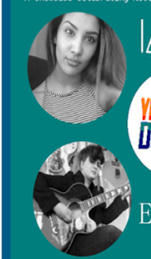

IAMSTARZZ

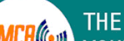

YOUNG

DIEITHL CREATIVES

EMILY FRANKLIN

\section{SATURDAY 9TH MAY}

8PM

NEVILLE STUDIO

Wellington Circus NG1 5A
The venue is actually up on the roof in a tincovered structure, recently covered over to make a performing space and mini-theatre. We are escorted to the room, the only group wearing hoodies and caps in the venue.

The room is not how I imagined compared to the last event. Its set up in theatre style seating and it feels very odd to be sitting down at a gig. The young people I am with sit on the back row. I see the performers sitting on the front row when I enter and I say 'hello'. I can see them looking nervous, sipping on water to keep their throats from drying up.

Figure 2. Live \& Local with fieldnotes.

with participants revealed to me that they were in fact meticulously crafted through filming and editing and streamed for YouTube, not as spontaneous and heated as I had expected. This learning prepared me for what I would then go on to experience together with the participants. The two excerpts below demonstrate my discussion of the forthcoming performance with the participants themselves, where we talked around video clips in order to prepare me for what to expect:

Pete: $\quad$ 'So in grime clashes, when the crowd react, because it's on a beat, you have to keep your flow. So then you have to start again, and that's the only way it can work. . I have to keep starting again because of the crowd. When they all go crazy'.

(Interview transcript)

Tyrone: 'Clash Money . . . it's about clashes, there's different clashes through the night and I was there because every interval there's a DJ part . . so I'd play for fifteen minutes. So when you're doing a party or a straight set, you have to bounce from different genres, but there, you just have to go grime . . . So to get prepared . . I found out like four weeks before and I just got all the tracks that I know will get people happy, and I just start downloading them. I've watched a lot of sets (on social media) so I knew it was a grime thing and I knew what to play as well. So it didn't take much preparing, but it took some'.

(Interview transcript)

Drawing on the notion of the embodied experience, I was aware that 'being there' was the main vehicle for forefronting the young people's lived experience of performing. My approach was to engage with a variety of different senses, as a way to capture data that could be revisited with the performer at a later date in order to deconstruct and de-cypher 
meaning. I regarded my ethnographic research as an extension of my youth work practice as it enabled me to spend time with the participants, engaging with the performance and dedicating time to informal discussion and shared reflection. My personal immersion in the live music and atmosphere of the events, enabled the experience to be 'embodied', with an emphasis on the active involvement of the researcher 'doing things' (Turner, 2000). In aiming to explore impacts of the experience of performing, I engaged with the embodied nature of experience, in recognition of affective knowing as a place of inquiry and possibility (Cancienne and Snowber, 2003). This position upholds the 'performing body' as a point of release from which participants' values and forms knowledge production that are embodied can be analysed (Roberts, 2013). In relation to this particular study, my embodied experience of young people performing rapping, singing and DJing, offered a way into their grounded aesthetics of their specific contexts and communities. This included recording as much of the ritualistic, atmospheric and sensory experience as possible, as the below fieldnotes show:

The compare hushes the crowd and gathers everyone around the two 'battlers' in the centre of the dancefloor. There is a brief interlude of silence in the chaos as no-one must talk or boo during the recordings. I stand at the back as the group gathers closely around each other, making it like a huddle. Hot and sticky. This adds to the hype. I am hot in just a t-shirt, so they must be boiling with hoodies, hats and even coats on. Their 'crew' bounces behind them as the 'spit' their words at the opponent.

(Fieldnotes)

My embodied experience was at times unfamiliar and uncomfortable. In particular, with the rap battle event, there was misogynistic content and a hyper-masculine atmosphere perpetuated by the sometimes offensive and troubling content of rap lyrics, which engendered feelings of discomfort within me. The rap battle performances, in particular, contained languages of hate and spoken violence - although this never materialised into physical violence - which were uncomfortable to experience, as the below fieldnotes show. This risked obscuring my process of seeing the value of performing at this event for the young people. Drawing on a grounded aesthetics approach within this situation enabled me to recognise the forms of symbolic creativity young people were engaging in through subcultural practices, often as an attempt to re-invent themselves. Putting my own tastes and values aside, I was able to see that participants were developing subcultural capital as an embodied form of being 'in the know' through their own performances (Crossley and Bottero, 2015; Hodkinson and Deicke, 2007; Thornton, 1996).

There is a marked difference between the older more established rappers and the younger ones. Some as young as 15. The young ones are more aggressive, more sexual in their content. Like they've got something to prove. For them, this is more about violence. Violence with words. Some of the audience are cool to it, hanging back. But others are right in the mix bouncing with the rapper's crew. Not everyone identifies with this culture. It's loud, it's rude and aggressive. Each rapper's art is a form of resistance, but in different ways.

(Fieldnotes) 
One way to engage with grounded aesthetics was in negotiating access to the events. This where my youth work practice was key in developing relationships with participants. Access was negotiated through invitations from the participants and could only be achieved following the building of rapport with young people during a sustained period of fieldwork. This was one of the luxuries and privileges of an ethnographic approach. As well as being part of the audience for the performance, participants appreciated my attendance as a form of support for them. For the first event I asked a young person I knew, who was not a research participant, but who was familiar with the style of music - grime, to accompany me. This meant that as an 'older' attender of these events, I would be more accepted. Participating in the performance events as an audience member was a key element of my approach as a way of embodying my learning about the different cultures of performing. However, once the embodied perspective was experienced, I had to develop various media and documentation strategies.

\section{Experimenting with media and documentation strategies}

Many ethnographers find their own ways to generate and capture data. It is an art and one which is reflective of personal and cultural experiences. During the performance events I had hoped to capture a rich description of the setting, the behaviours and interactions of the performers alongside the timeline of the event. Figure 2 displays the flyer for the second event I attended, which was a music performance night at local theatre venue. The participants I was accompanying were JB, an 18-year-old male rapper and Grace, a 15 -year-old female singer. The figure juxtaposes the flyer with my fieldnotes in order to give a snapshot of arriving at the venue and begin to highlight the differences with the other events. This written account was scribed immediately after the event, and describes the 'clash of cultures' between the young people's gig and the regular theatre-goers. Alongside fieldnotes, multimodal forms of data such as images and film clips were taken by myself and other young people who were attending. Capturing this wide range of data at the time was vital for the participatory analysis process that followed. Collecting this data was in part serendipitous as it relied on other audience members generating data and sharing this with me following the event. However, my intention was that sourcing data be a collective rather than individual process. This would further support my collaborative approach to data analysis and representation.

Taking a multimodal approach, I was able to collate a number of artefacts prior to attending the event, which served as springboards for discussion with participants. I recognised that social media had a big role in promoting and organizing the events as participants shared 'e-flyers' ${ }^{4}$ before attending. These digital practices of self-promotion were central to how the participants viewed their performance events as a social endeavour (Manchester and Pett, 2015). Examining these as artefacts was part of the fieldwork as I was able to glean particular understandings around the aesthetics of the events, the intended audience, but also hierarchies of performing. For example, the 'headliners' appear at the top of the flyers and less significant and often young performers do not get a mention. I learnt through discussing these promotional flyers with participants that to have your name feature on an event flyer represents great prestige, as one participant shared with me his excitement at being listed on event promotional material for the first 
time. These artefacts represented the textual and digital production of cultures for young people as representations of cultural systems (Garnham, 2005; Koro-Ljungberg and Greckhamer, 2005). My approach, therefore, was a useful method for collating artefacts, in particular digital artefacts such as event flyers and YouTube clips as part of the multimodal ethnographic process.

Instead of focusing on ethnographic notetaking during events, which would have been an obstructive intrusion, I chose to focus on participation and the sensory experience. The introduction of pen and paper to the scene would have caused an unnatural reaction from participants and a distraction. During the event I used my mobile phone to make brief notes, to capture significant moments. This appeared as if writing and sending a simple text message. Figure 3 is an example of notes taken during the rap battle event where I describe the current happening. The collection of notes generated was collated at a later date in order to explore the timeline of the event. I also captured audio recordings with a small device as well as video footage taken by participants, other young people and event organizers at a later date. These enabled me to provide rich description of the events.

In the absence of detailed fieldnotes taken during the event, the hours directly after were vital for me to sit down and write, in order to try to capture that experience. Sometimes I did this at home or sitting in my car straight after the event. This 'in-between writing' (Coles and Thomson, 2016) was key to the process of ethnographic sense-making as it enabled the capturing of written description with a larger analysis in mind. These events were often filmed, both officially by the organisers and unofficially by the young people taking part. Social media, therefore, became a rich source of data for the events. Engaging with digital ethnography as an approach to studying digital communication (Varis, 2016), I was able to glean the 'grounded aesthetics' of each of the events, connecting both online and offline fieldwork settings. As Pink argues (2011) this enables us to rethink the ethnographic encounter. In particular, the use of participant-created videos can be considered as narrative constructions that reveal multiple perspectives (Gallagher et al., 2013).

\section{Collaborative and participatory perspectives in analysis}

My intention was to use this bottom-up approach in defining participants' own values, through drawing on grounded aesthetics (Willis, 1998a). This determined young people's cultural experiences in respect of performing at these events. Post-event reflection was aided by the audio-visual material that was gathered and enabled analysis processes to be participatory and collaborative. After the event, talking to the performers was vital in capturing their experience and measuring its value for them. The example shared here is form the third event I visited. This was a Youth Club performance night at an old disused bar. Being towards the end of my fieldwork, I had developed a strong rapport with the performers and the participants that I was accompanying to this event who were Greg, a Project Worker and musician in two bands, Serena a 14-year-old female rapper and JB an 18-year-old male rapper.

My approach was to draw on the range of data generated during the event - fieldnotes, audio recordings and video recordings, with the participants in the days 
$\bullet \bullet \bullet \circ 3$ 3G

10:17

$94 \%$

\section{Back}

\section{May 2015 19:55}

Some guy like a poet. Another one choaks. But everyone's supporting him. No bad vibes. It's an act. They're actors but there can only be one winner. Room is hot temp is stifling. Everyone flies outside for fags in the break. There's a whole other world going on out there. In here is controlling shushhhhed for film. For longevity on the Internet. To build the brand Clash money
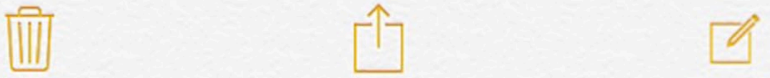

Figure 3. Mobile phone notes.

following the event. These served as aide-memoires to re-situate the performer within that environment. As part of this process as we watched footage together, both on YouTube and on mobile phones, listened to tracks from the performance and shared event flyers (Figure 4). I often read out my fieldnotes so that the young person could 


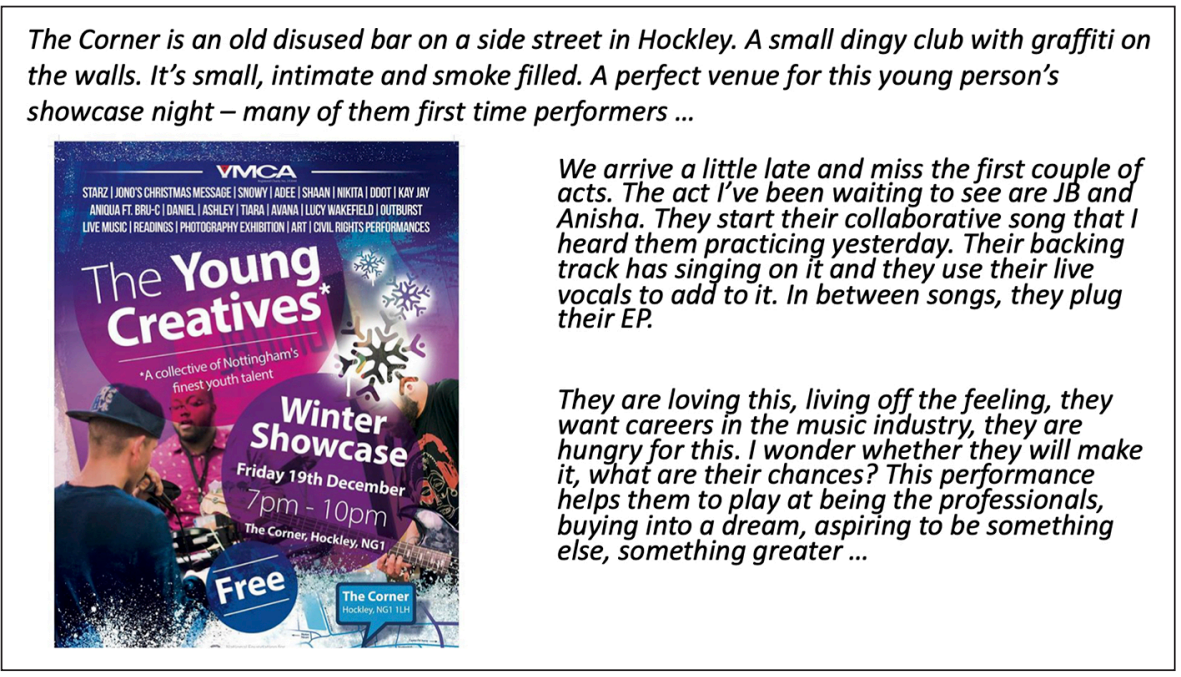

Figure 4. Event flyer 'Young Creatives'.

respond to how I had represented the experience. This approach offered participants a variety of media and frames of reference through which to talk about their experience. For example, the below excerpt shows a participant describing their feelings as they are performing and the value of making their voice heard:

Frances (Researcher):

$J B$ (Participant and performer):
So how do you feel when you've come off stage? How do you feel now? Like all those nerves that have been building up?

Everything goes, you know when you start rapping. Everything goes down. The nervousness is there before I go on because I think is anyone really going to listen to what I am going to say? Is anyone going to jam to it? Just being able to tell my story and to have people listen . . . the buzz is there because you are basically telling someone about yourself and they are forced to listen. Do you know what I mean? They can't answer back and be like "no". They're just listening to you . . . (Interview)

Drawing further on digital ethnography and considering how to represent an embodied and sensorial experience, my approach to analysis was creative, collaborative and participatory. This reflective post-event experience enabled the creation of embodied forms of knowledge (Degarrod, 2013), which was an important mechanism for triangulation. The making of the film clips was a key vehicle to test my ideas and understanding of 


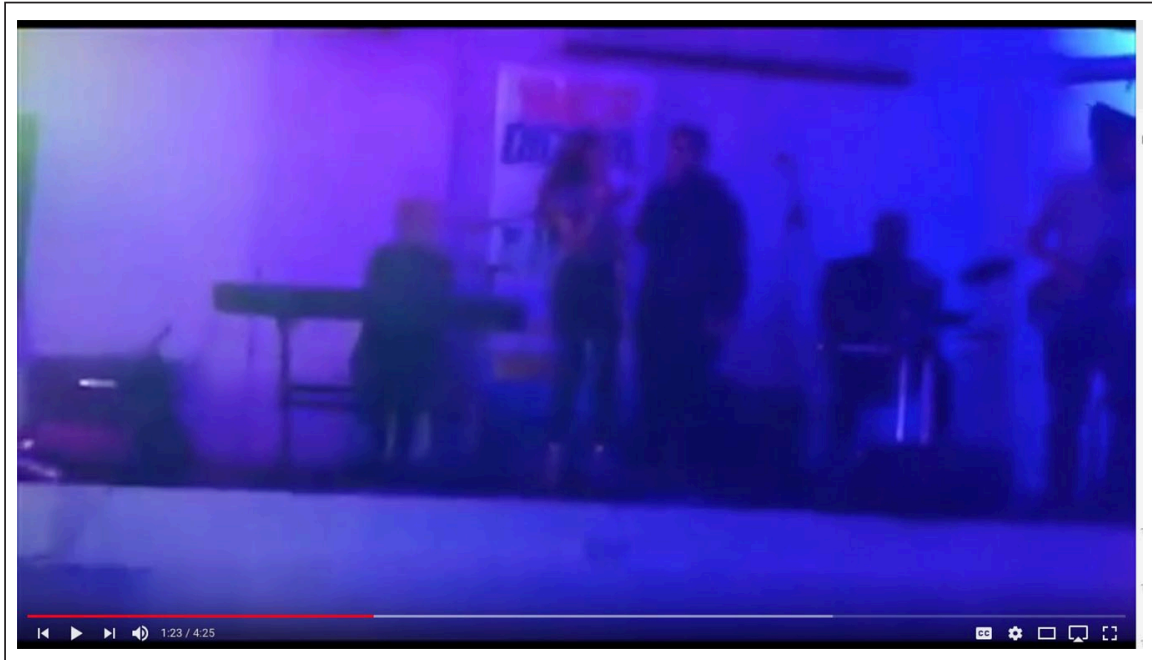

Figure 5. Screenshot from Film Clip.

Hyperlink for film clip to be included in online journal: https://www.youtube.com/watch?v=XMIlwxk5L2A\&f eature=youtu.be.

participants' views and experiences. For example, I created five short films with these materials, compiling many different sources and varieties of data - audio, film footage, transcribed words - as a way of representing the young person's experience. Having collaborative processes of analysis was key to acknowledging and privileging the participants' individualised experience through the eyes of the researcher. Figure 5 is one of the co-productions and as this short video demonstrates, I had compiled different sources and modes of data as a way of representing the young person's experience. This process also generated an end product that could be shared as part of the research.

In this way, the video clips created can be seen as 'hypermedia environments' from which meaning emerges through new 'multi-semiotic' modes (Dicks et al., 2006). The short films represent a bricolage, a layering and overlapping of different elements of the performers' experience in order to pay attention to their significant moments and different perspectives. Multi-modality requires the switching of modes, backwards and forwards, from audio to visual to textual as both representation and interpretation. Editing the films in discussion with the participants was a key stage in becoming familiar with the data collected, but also a key part of the analysis. As such it was a way to incorporate diverse perspectives through layering data sources and an approach which intentionally contributed to the representation of experiential learning in empiric form.

My approach to this ethnographic project therefore was not only through diverse strategies for data collection, but also collaborative methods for analysis. As part of a wider ethnographic study, I focused on event-centred projects in order to explore what the young people got out of performing, their motivations for taking part in these events and what young people valued about these experiences. The embodied and sensorial experience of fieldwork, alongside multimodal data collection, complemented the participatory 
processes that followed the events and enabled the exploration of the particular grounded aesthetics of these three showcasing events.

\section{Conclusion}

This paper has attempted to illustrate an approach to researching event-centred projects. The dilemma that I faced during fieldwork was in exploring participants' diverse cultural values and affective responses to performing at live music events. I engaged with sensorial and embodied ethnography and grounded aesthetics as a way of doing this. I sought to question why young people take part in these events, how they judged their own performance in relation to others and what they valued about the experience. In this paper I explained my particular decisions for undertaking research into an arts education programme, which contained, as many do, a showcasing element. I recognised that how research is conducted has implications for the need to be responsive to participants' own forms of cultural communication (McGillen and McMillan, 2003).

Ethnography, as well as exploring the experience of others, can communicate key messages from the research in multimodal form. It is both 'tool' and 'vehicle'. This was highlighted through my engagement with various media and documentation strategies which adopt a participatory and collaborative approach. The use of visual and audio material is vital for encouraging dialogue that can unpack meaning within experience with participants and also communicate its messages to the audience for the research. My approach to ethnography as a research method enabled the use of 'presentational' knowledge as symbolized knowing (Liamputtong and Rumbold, 2008), which represents experiential learning in expressive forms. I argue for this approach in forefronting lived experience, acknowledging diverse cultures and challenging the representation of knowledge through ethnographic research, which is a relatively underdeveloped area in academic research. Undertaking ethnographic case study integrating arts-based methods is not a new endeavour (Barone and Eisner, 2011; Finley et al., 2011; Heath and Roach, 1999). However, this is an important and emerging field of creative research in representing empiric learning through evocative outputs.

Through sharing my ethnographic encounters and my approach to researching eventbased projects, in this paper, I offer an example which could be extended to the study of seasonal rituals, festivals and other types of organisational settings in which creative work culminates in some type of public display. By focusing on the performance as central, as part of a project, the value of participating can be recognised through engaging with grounded aesthetics. This paper offers a methodological contribution regarding how to unpack the grounded aesthetics of specific contexts and communities. My approach represented an opportunity to make visible these often taken-for-granted routines, practices and tastes, which the sensory and relational aspects of grounded aesthetics can be used to capture. In exploring participants' displays of grounded aesthetics through performing, a way of critically judging experiences that are shared with others was celebrated as a form of social practice.

\section{Declaration of Conflicting Interests}

The author declared no potential conflicts of interest with respect to the research, authorship, and/ or publication of this article. 


\section{Funding}

The author received no financial support for the research, authorship, and/or publication of this article.

\section{ORCID iD}

Frances Howard (iD https://orcid.org/0000-0002-8493-5721

\section{Notes}

1. Arts Award website: www.artsaward.org.uk.

2. The Bronze, Silver and Gold levels of the Arts Award align to Ofqual award levels, which increase in total qualification time as the levels progress. For example, Bronze equates to EQF (European Framework Qualification) level 2 and requires 60 hours total qualification time.

3. The names of the participants have been changed.

4. An 'e-flyer' is a free to produce promotional material which can be easily created and circulated online as part of the do-it-yourself (DIY) culture of live music events.

\section{References}

Ardèvol E and Gómez-Cruz E (2012) Digital ethnography and media practices. In: The International Encyclopedia of Media Studies, 498-518.

Arts Award (2016) Annual Guide. www.ArtsAward.org.uk

Barone T and Eisner EW (2011) Arts Based Research. California: Sage Publications.

Barter C and Renold E (1999) The use of vignettes in qualitative research. Social Research Update 25(9): 1-6.

Bennett A and Peterson RA (2004) Music Scenes: Local, Translocal and Virtual. USA: Vanderbilt University Press.

Biggs M (2002) The role of the artefact in art and design research. International Journal of Design Sciences and Technology 10(2): 19-24.

Cancienne MB and Snowber CN (2003) Writing rhythm: movement as method. Qualitative Inquiry 9(2): 237-253.

Coles R and Thomson P (2016) Beyond records and representations: inbetween writing in educational ethnography. Ethnography and Education 11(3): 253-266.

Crossley N and Bottero W (2015) Social spaces of music: introduction. Cultural Sociology 9(1): 3-19.

Curtis K, Roberts H, Copperman J, et al. (2004) 'How come I don't get asked no questions?'Researching 'hard to reach'children and teenagers. Child \& Family Social Work 9(2): 167-175.

Degarrod LN (2013) Making the unfamiliar personal: arts-based ethnographies as public-engaged ethnographies. Qualitative Research 13(4): 402-413.

Delgado M (2015) Urban Youth and Photovoice: Visual Ethnography in Action. USA: Oxford University Press.

Dicks B, Soyinka B and Coffey A (2006) Multimodal ethnography. Qualitative Research 6(1): 77-96.

Estalella A and Criado TS (2018) Experimental Collaborations: Ethnography through Fieldwork Devices (Vol. 34). New York: Berghahn Books.

Finlay I, Sheridan M, Coburn A, et al. (2013) Rapid response research: using creative arts methods to research the lives of disengaged young people. Research in Post-Compulsory Education 18(1-2): 127-142. 
Finley S, Denzin N and Lincoln Y (2011) Critical arts-based inquiry. The SAGE Handbook of Qualitative Research 435-450. California: SAGE.

Flewitt R (2011) Bringing ethnography to a multimodal investigation of early literacy in a digital age. Qualitative Research 11(3): 293-310.

Gallagher K, Wessels A and Ntelioglou BY (2013) Becoming a networked public: digital ethnography, youth and global research collectives. Ethnography and Education 8(2): 177-193.

Garnham N (2005) From cultural to creative industries: an analysis of the implications of the "creative industries" approach to arts and media policy making in the UK. International Journal of Cultural Policy 11(1): 15-29.

Gormally S and Coburn A (2014) Finding Nexus: connecting youth work and research practices. British Educational Research Journal 40(5): 869-885. doi:10.1002/berj.3118

Heath SB and Roach A (1999) Imaginative actuality: learning in the arts during the nonschool hours. In: Fiske E (ed.), Champions of Change: The Impact of the Arts on Learning. Washington DC: Arts Education Partnership and President's Committee on the Arts and Humanities, 19-34.

Hickey-Moody A (2013) Youth, Arts, and Education: Reassembling Subjectivity through Affect. Oxon: Routledge.

Hodkinson P and Deicke W (2007) Youth Cultures: Scenes, Subcultures and Tribes (Vol. 10). New York: Routledge.

Ingold T (2011) Worlds of sense and sensing the world: a response to Sarah Pink and David Howes. Social Anthropology 19(3): 313-317.

Jeffrey B (2006) Creative teaching and learning: towards a common discourse and practice. Cambridge Journal of Education 36(3): 399-414.

Jones S (1990) Music and symbolic creativity. In: Willis P (ed.) Common Culture: Symbolic Work at Play in the Everyday Cultures of Young People. Buckingham: Oxford University Press, 59-83.

Jones JL (2002) Performance ethnography: the role of embodiment in cultural authenticity. Theatre Topics 12(1): 1-15.

Koro-Ljungberg M and Greckhamer T (2005) Strategic turns labeled 'ethnography': from description to openly ideological production of cultures. Qualitative Research 5(3): 285-306.

Lamb J, Gallagher MS and Knox J (2018) On an excursion through EC1: multimodality, ethnography and urban walking. Qualitative Research, https://doi.org/10.1177/1468794118773294.

Liamputtong P and Rumbold J (2008) Knowing Differently: Arts-Based and Collaborative Research Methods. New York: Nova Publishers.

Mäkelä M (2007) Knowing through making: the role of the artefact in practice-led research. Knowledge, Technology \& Policy 20(3): 157-163.

Manchester H and Pett E (2015) Teenage kicks: exploring cultural value from a youth perspective. Cultural Trends 24(3): 223-231.

McGillen C and McMillan R (2003) Cooperative song writing: adventures in anarchy and engagement with adolescents. Australian Journal of Music Education 1: 25.

Mills D and Morton M (2013) Ethnography in Education. London: Sage Publications.

Mitchell C, Chege F, Maina L, et al. (2016) Beyond engagement in working with children in eight Nairobi slums to address safety, security, and housing: digital tools for policy and community dialogue. Global Public Health 11(5-6): 651-665.

Nyariro M, Muthuri S, Hani Sadati S, et al. (2017) Picturing change through PhotoVoice: participatory evaluation of a daycare intervention in Kenya. GrOW Research Series Policy Brief. Montreal, Canada: Institute for the Study of International Development, McGill University.

O'Neill S and Green L (2001) Social groups and learning in music education. Mapping Music Education Research in the UK. 
Pink S (2011) From embodiment to emplacement: re-thinking competing bodies, senses and spatialities. Sport, Education and Society 16(3): 343-355.

Pink S (2015) Doing Sensory Ethnography. London: Sage Publications.

Pink S, Hubbard P, O'Neill M, et al. (2010) Walking across disciplines: from ethnography to arts practice. Visual Studies 25(1): 1-7.

Roberts RA (2013) Dancing with social ghosts: performing embodiments, analyzing critically. Transforming Anthropology 21(1): 4-14.

Rose G (2012) Audience studies. Visual Methodologies: An Introduction to Researching with Visual Materials. London: Sage Publications.

Russell L (2013) Researching marginalised young people. Ethnography and Education 8(1): 4660. doi:10.1080/17457823.2013.766433

Theron L, Mitchell C, Smith AL, et al. (2011) Picturing Research. Boston: Springer.

Thomson P and Sefton-Green J (2010) Researching Creative Learning: Methods and Issues. London: Routledge.

Thornton S (1996) Club Cultures: Music, Media, and Subcultural Capital. Cambridge: Wesleyan University Press.

Turner A (2000) Embodied ethnography. doing culture. Social Anthropology 8(01): 51-60.

Varis P (2016) Digital ethnography. The Routledge Handbook of Language and Digital Communication, 55-68. New York: Routledge.

Willis P (1998a) Notes on common culture - towards a cultural policy for grounded aesthetics. International Journal of Cultural Policy 4(2): 413-430.

Willis P (1998b) Notes on common culture: towards a grounded aesthetics. European Journal of Cultural Studies 1(2): 163-176.

\section{Author biography}

Frances Howard is a Senior Lecturer in Youth Studies at Nottingham Trent University. She draws on creative approaches to teaching and learning and undertakes film making activities with students as a way to develop pedagogical resources. Frances has previously worked in local authorities, arts education and youth work and continues to be involved in evaluation and research for arts, youth and community projects. 